\title{
The Stimulatory Roles of Catecholamines and Acetylcholine in the Regulation of Gonadotropin Release in Ovariectomized Estrogen-primed Rats
}

\author{
Masazumi KAWAKAMI, Jun ARITA, Fukuko KIMURA \\ AND REIKO HAYASHI \\ Second Department of Physiology, Yokohama City University School \\ of Medicine, Yokohama 232, Japan
}

\section{Synopsis}

Injections of $2 \mathrm{mg}$ of progesterone into ovariectomized estrogen-primed rats significantly increased serum LH and FSH concentrations 3, 5 and $8 \mathrm{hr}$ later. Receptor blockers of noradrenaline (NA), dopamine (DA) or acetylcholine (ACH), phenoxybenzamine $(20 \mathrm{mg} / \mathrm{kg}$ body weight), pimozide $(1 \mathrm{mg} / \mathrm{kg}$ body weight) or atropine (700 $\mathrm{mg} / \mathrm{kg}$ body weight), respectively, prevented the progesterone-induced gonadotropin release. On the other hand, none of them blocked the gonadotropin release following unilateral electrochemical stimulation $(100 \mu \mathrm{A}$ for $60 \mathrm{sec})$ of the medial preoptic area which occurred 0.5 and $1.5 \mathrm{hr}$ later, although pimozide or atropine reduced serum LH concentrations at $4.0 \mathrm{hr}$ after stimulation.

Furthermore, the sites of action of NA, DA and $\mathrm{ACH}$ with respect to LH release were examined by intracerebral implantation in ovariectomized estrogen-primed rats. $\mathrm{DA}$ or $\mathrm{ACH}$, when implanted unilaterally into the medial preoptic area, induced a significant increase in serum LH $5 \mathrm{hr}$ later, whereas NA decreased LH levels. Implantations of NA or ACH into the bed nucleus of the stria terminalis or the medial amygdala increased serum $\mathrm{LH}$ although the effect of NA into the latter was not statistically significant. Only implantations of NA among the three substances into the lateral septum induced $\mathrm{LH}$ release.

These results suggest that all of NA, DA and $\mathrm{ACH}$ play stimulatory roles in the regulation of gonadotropin secretion, and that there are regional differences of their effectivenesses in releasing $\mathrm{LH}$ within the limbic-preoptic area.

Since Sawyer et al. (1947) presented experimental results suggesting that an adrenergic mechanism plays an important role in the regulation of gonadotropin secretion, it has been long a big subject in the neuroendocrinology of reproduction what chemical substances are involved in the neural transmission for gonadotropin release.

Although there is a general agreement on the distribution of catecholamines in the brain, controversies exist concerning their roles in the regulation of gonadotropin secretion. Sawyer et al. (1947) reported

Received September 22, 1978. that ovulation following coitus in the rabbit was prevented by prompt intravenous injection of an adrenergic blocking agent, dibenamine. They also demonstrated that intraventricular injection of adrenaline or noradrenaline (NA) induced ovulation in the estrogen-primed rabbit (Sawyer, 1952), but the injection of dopamine (DA) failed to stimulate an ovulatory $\mathrm{LH}$ surge and actually inhibited the stimulatory effect of NA (Sawyer et al., 1974). Furthermore, it has been shown that intraventricular injection of adrenaline or NA, but not of DA, was effective in inducing ovulation or LH surge in the proestrous pentobarbital- 
blocked rat (Rubinstein and Sawyer 1970), in the ovariectomized steroids-primed rat (Krieg and Sawyer, 1976) and in the rat made anovulatory either by electrolytic lesions in the anterior hypothalamus or by exposure to continuous illumination (Tima and Flerkó, 1974). However, other investigators reported that intraventricular DA injection was effective in stimulating $\mathrm{LH}$ secretion in the female (Schneider and McCann, 1970) and male rat (Kamberi et al., 1970), whereas an equivalent amount of NA or adrenaline was ineffective to induce $\mathrm{LH}$ release. In addition, such a discrepancy with respect to the stimulatory effect of NA and DA was also observed in in vitro studies (Schneider and McCann, 1969; Miyachi et al., 1973; Rotsztejn et al., 1977) and in studies using blockers of catecholamines (Kordon and Glowinski, 1969; Kalra and McCann, 1974).

On the other hand, the involvement of a cholinergic mechanism in the regulation of gonadotropin secretion has been suggested in an early experiment in which ovulation was blocked by injection of a cholinergic blocking agent, atropine in the rat (Everett et al., 1949). Furthermore, it was recently shown that intraventricular injection of acetylcholine $(\mathrm{ACH})$ induced a significant increase in serum $\mathrm{LH}$ in the male rat (Justo et al., 1975).

In most of the studies cited above, catecholamines or $\mathrm{ACH}$ was injected into the third ventricle. Intraventricular injections as well as in vitro experiments did not allow any discrete localization of the sites of action of the substances. Consequently, the present study was undertaken in order to examine where $\mathrm{NA}, \mathrm{DA}$ and $\mathrm{ACH}$ are involved in the regulation of gonadotropin release in the limbic-preoptic-hypothalamic system of ovariectomized estrogen-primed rats. The results of the present study seem to partly explain the discrepancies concerning the roles of catecholamines and $\mathrm{ACH}$ in the regulation of gonadotropin release.
Preliminary studies have been presented previously (Kawakami et al., 1975 and 1976).

\section{Materials and Methods}

Wistar female rats weighing 210-320 $\mathrm{g}$ were housed under controlled conditions of light (lights on from 0500 to $1900 \mathrm{hr}$ ) and temperature $\left(23-25^{\circ} \mathrm{C}\right)$ and given free access to water and laboratory chow. Animals were used two or three weeks after ovariectomy.

\section{Experiment $I$}

In order to examine the involvement of NA, DA and $\mathrm{ACH}$ in the regulation of progesterone $(\mathbf{P})$-induced gonadotropin release, three different receptor blockers were administered to estrogen and P-treated rats. Animals were injected s.c. with $20 \mu \mathrm{g}$ of estradiol benzoate (EB) at $1200 \mathrm{hr}$ followed by s.c. injections of $2 \mathrm{mg}$ of $\mathbf{P} 72 \mathrm{hr}$ later. Immediately before the injection of $\mathrm{P}$, an $\alpha$-adrenergic blocker, phenoxybenzamine hydrochloride (Tokyo Kasei Kogyo Co. Ltd., $20 \mathrm{mg} / \mathrm{kg}$ body weight, i.p., in $50 \%$ ethanol), a specific dopaminergic receptor blocker, pimozide (Fujisawa Pharmaceutical Co. Ltd., $1 \mathrm{mg} / \mathrm{kg}$ body weight, i.p., in $0.1 \mathrm{M}$ tartaric acid), a cholinergic receptor blocker, atropine sulphate monohydrate (Wako Pure Chemical Industries Ltd., $700 \mathrm{mg} / \mathrm{kg}$ body weight, s.c., in saline) or saline was administered. Another group was injected with EB but treatments with $\mathrm{P}$ and receptor blockers were omitted. Blood samples were taken immediately before injecttion of blockers and subsequently at 1500, 1700 and $2000 \mathrm{hr}$ for measurement of serum LH and FSH.

\section{Experiment II}

In this experiment rats were pretreated with blockers to determine whether NA, DA and $\mathrm{ACH}$ participate in the regulation of the gonadotropin release in response to the electrochemical stimulation of the preoptic area. The animals were anesthetized with sodium pentobarbital $(30 \mathrm{mg} / \mathrm{kg}$ body weight, i.p.). A bipolar concentric stainless steel electrode was stereotaxically oriented into the medial preoptic area (MPO) according to the atlas of Albe-Fessard et al. (1966) and fixed to the skull with dental cement. Three weeks after the operative procedures, rats primed with $20 \mu \mathrm{g}$ EB $70 \mathrm{hr}$ before were administered at $1000 \mathrm{hr}$ with the same receptor blockers as described in Experiment I. Electrochemical stimulation was then performed unilaterally by passing a direct current of $100 \mu \mathrm{A}$ for $60 \mathrm{sec}$ through stimulating electrode between 1100 and $1200 \mathrm{hr}$. Blood samples were taken immediately before stimulation and subsequently at 0.5 . 1.5 and $4.0 \mathrm{hr}$ after electrochemical stimulation. 


\section{Experiment III}

This experiment was undertaken in order to determine the effective substance(s) among NA, DA and $\mathrm{ACH}$ for stimulating $\mathrm{LH}$ release when they are implanted into the various parts of the limbic-preoptic system. The limbic-preoptic system has been shown to be involved in the stimulatory feedback action of estrogen and $\mathbf{P}$ on gonadotropin release in ovariectomized EB-primed rats (Kawakami et al., 1978a and b). A double cannula was utilized for the intracerebral implantation of catecholamines and $\mathrm{ACH}$ as described elsewhere (Kawakami at al., 1978a). A stainless steel tube as an outer cannula was stereotaxically oriented unilaterally into the MPO, the bed nucleus of the stria terminalis (BST), the medial amygdala (m-AMYG) or the lateral septum (1-SEPT) under pentobarbital anesthesia. Three weeks after the implantation of the guiding outer cannula, animals were primed with $20 \mu \mathrm{g}$ of EB at $1200 \mathrm{hr}$ and intracerebral implantations of the inner cannula were performed $72 \mathrm{hr}$ later. For packing the substances, the inner cannula was tapped twenty times into a small amount of crystal of NA (1-noradrenaline bitartrate, Wako Pure Chemical Industries Ltc.), DA (dopamine hydrochloride, ibid) or ACH (acetylcholine hydrochloride, Dai-ichi Pharmaceutical Co. Ltd.) on a glass slide and thereafter inserted through the outer cannula into the brain without anesthesia. The first blood sample was taken 30 min before implantation, and the remaining sample was taken $5 \mathrm{hr}$ after implantation.

Blood samples of $0.5 \mathrm{~m} l$ were taken by heart puncture under light ether anesthesia, and the serum was separated by centrifugation and stored at $-20^{\circ} \mathrm{C}$ until assayed. Serum LH and FSH were measured by radioimmunoassay kits supplied by the NIAMDD, U.S.A. The method was principally based on the double antibody procedure described in the instructions of the kits. The referential standards were NIAMDD rat LH RP-1 and NIAMDD rat FSH RP1. Serum LH and FSH concentrations were expressed in terms of NIH-LH-SI and NIH-FSH-SI, respectively.

At the time of sacrifice, the brains were perfused with $10 \%$ formalin. The sites of implantations and electrochemical stimulation were microscopically identified in tissue slices.

The data were statistically analyzed using Student's $t$-test for comparison of means between different groups and the paired $t$-test for comparison of means of different time within the same group.

\section{Results}

\section{Experiment I}

As shown in Fig. 1, EB priming induced a slight and transient increase in serum
LH concentration 3 and $5 \mathrm{hr}$ later $(\mathrm{p}<0.01)$, whereas in animals injected with $2 \mathrm{mg} \mathrm{P}$ following EB priming, there was a marked elevation in serum LH $3(\mathrm{p}<0.001)$ and $5 \mathrm{hr}$ later $(\mathrm{p}<0.02)$. The elevated concentrations declined $8 \mathrm{hr}$ later, but still remained significantly higher levels $(\mathrm{p}<0.02)$ when compared with those obtained from the animals without $P$ injection. Injections of phenoxybenzamine or atropine immediately before $\mathrm{P}$ injection completely blocked the P-induced LH release $(\mathrm{p}<0.02)$. Pimozide also prevented the $\mathrm{LH}$ release significantly $3(\mathrm{p}<0.01)$ and $5 \mathrm{hr}$ later $(\mathrm{p}<0.05)$, but the significant difference of LH levels between pimozide-injected group and salineinjected control group could not be observed at $8 \mathrm{hr}$ after $\mathrm{P}$ injection $(\mathrm{p}>0.10)$.

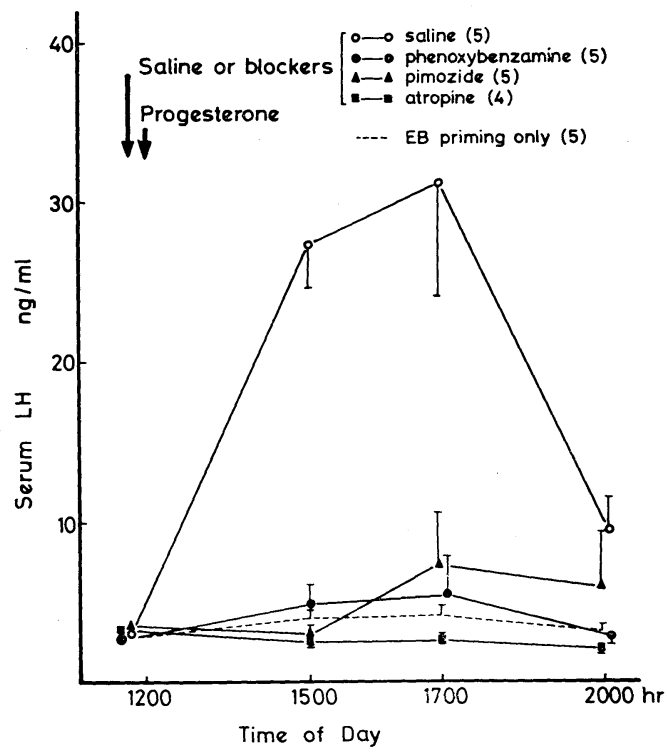

Fig. 1. Effects of adrenergic, dopaminergic and cholinergic receptor blockers on progesterone $(\mathrm{P})$ induced LH release in ovariectomized estradiol benzoate primed rats. Broken line represents the mean of concentrations of animals primed with estradiol benzoate but not treated with $\mathrm{P}$ and any blockers. Phenoxybenzamine $(20 \mathrm{mg} / \mathrm{kg}$ body weight), pimozide (1 mg/kg body weight), atropine $(700 \mathrm{mg} / \mathrm{kg}$ body weight) or saline was injected immediately before injections of $2 \mathrm{mg} \mathrm{P}$ at $1200 \mathrm{hr}$. Each point represents mean and vertical bar, SEM. The number of animals is given in parentheses. 
Although there was a gradual increase in serum FSH in EB-primed rats, $\mathrm{P}$ injections induced a further significant increase in serum FSH 3,5 and $8 \mathrm{hr}$ later $(\mathrm{p}<$ 0.02) (Fig. 2). Among injections of receptor blockers, only atropine significantly suppressed the P-induced FSH release $3 \mathrm{hr}$ later $(\mathrm{p}<0.05)$. At 5 and $8 \mathrm{hr}$ after injections of blockers, FSH values tended to rise, but they were significantly lower than those of saline-injected control group $(\mathrm{p}<0.05)$.

\section{Experiment II}

Sham stimulation slightly increased serum $\mathrm{LH}$ at 0.5 and $1.5 \mathrm{hr}$ later $(\mathrm{p}<0.05)$, but did not alter serum FSH at any time. Electrochemical stimulation of the MPO $(100 \mu \mathrm{A}$ for $60 \mathrm{sec})$ in saline-injected control group produced a dramatic rise in serum LH 0.5 and $1.5 \mathrm{hr}$ later $(\mathrm{p}<0.001)$ (Table 1). The elevated serum LH concentrations fell $4.0 \mathrm{hr}$ later, but still remained higher than the prestimulation levels $(\mathrm{p}<0.02)$. Serum LH levels before stimulation were not statistically different among the groups

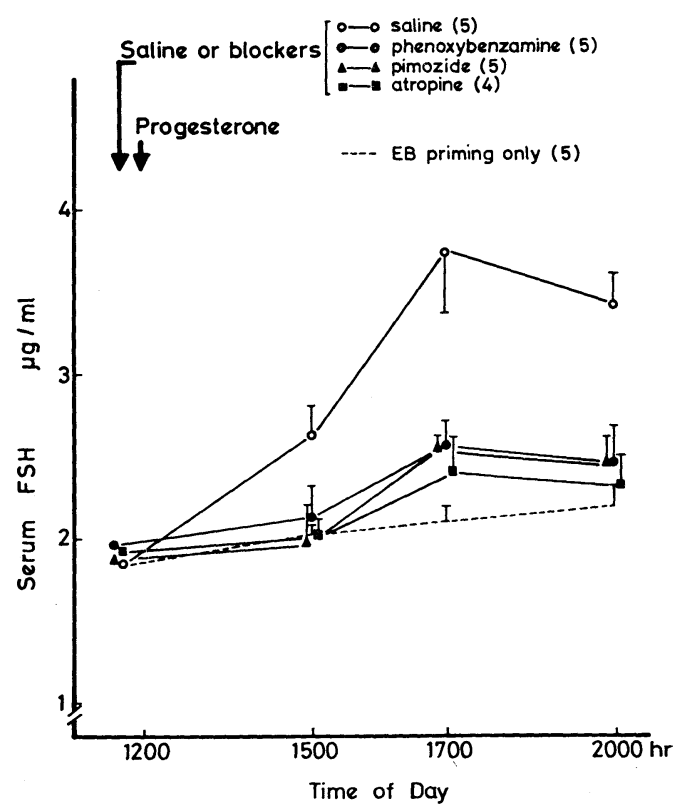

Fig. 2. Effects of adrenergic, dopaminergic and cholinergic receptor blockers on P-induced FSH release in ovariectomized estradiol benzoate-primed rats. Each point represents mean and vertical bar, $S E M$. The number of animals is given in parentheses.

Table 1. Effects of adrenergic, dopaminergic and cholinergic receptor blockers on gonadotropin release induced by electrochemical stimulation of the medial preoptic area in ovariectomized estradiol benzoate-primed rats.

\begin{tabular}{|c|c|c|c|c|c|}
\hline \multirow[b]{2}{*}{$\begin{array}{c}\mathrm{Hr} \text { after } \\
\text { stimulation }\end{array}$} & \multirow[b]{2}{*}{$\begin{array}{c}\text { Sham } \\
\text { stimulation } \\
(4)^{b}\end{array}$} & \multicolumn{4}{|c|}{ Preoptic electrochemical stimulation } \\
\hline & & $\begin{array}{c}\text { Salinea } \\
(9)\end{array}$ & $\begin{array}{l}\text { Phenoxy- } \\
\text { benzamine } \\
(6)\end{array}$ & $\begin{array}{c}\text { Pimozide } \\
(6)\end{array}$ & $\begin{array}{l}\text { Atropine } \\
\text { (5) }\end{array}$ \\
\hline \multicolumn{6}{|l|}{ Serum LH } \\
\hline 0 & $1.00 \pm 0.18 \mathrm{c}$ & $1.17 \pm 0.25$ & $2.15 \pm 0.47$ & $1.12 \pm 0.27$ & $0.98 \pm 0.15$ \\
\hline 0.5 & $2.42 \pm 0.21$ & $8.51 \pm 1.08$ & $10.81 \pm 1.29$ & $10.40 \pm 2.02$ & $6.21 \pm 0.51$ \\
\hline 1.5 & $1.98 \pm 0.14$ & $7.16 \pm 1.10$ & $10.46 \pm 2.12$ & $8.33 \pm 2.93$ & $4.79 \pm 0.89$ \\
\hline 4.0 & $1.25 \pm 0.17$ & $4.48 \pm 0.96$ & $4.34 \pm 1.06$ & $1.55 \pm 0.14^{*}$ & $1.64 \pm 0.17^{*}$ \\
\hline \multicolumn{6}{|l|}{ Serum FSH } \\
\hline 0 & $1.70 \pm 0.12 \mathrm{~d}$ & $1.78 \pm 0.15$ & $1.71 \pm 0.09$ & $1.68 \pm 0.24$ & $1.87 \pm 0.08$ \\
\hline 1.5 & $1.68 \pm 0.14$ & $2.40 \pm 0.18$ & $2.45 \pm 0.19$ & $2.23 \pm 0.16$ & $2.36 \pm 0.19$ \\
\hline 4.5 & $1.73 \pm 0.21$ & $2.58 \pm 0.22$ & $2.66 \pm 0.16$ & $2.20 \pm 0.11$ & $2.35 \pm 0.10$ \\
\hline
\end{tabular}

a Phenoxybenzamine $(20 \mathrm{mg} / \mathrm{kg}$ body weight), pimozide $(1 \mathrm{mg} / \mathrm{kg}$ body weight), atropine $(700 \mathrm{mg} / \mathrm{kg}$ body weight) or saline was injected between 1 and $2 \mathrm{hr}$ before electrochemical stimulation (100 $\mu \mathrm{A}$ for $60 \mathrm{sec}$ ).

b Number of animals

c Mean $\pm S E M$ (serum concentration $\mathrm{ng} / \mathrm{m} l$ )

d Mean $\pm S E M$ (serum concentration $\mu \mathrm{g} / \mathrm{m} l$ )

* $\mathrm{p}<0.05 \ldots$. v. saline-injected group 
of rats treated with one of the three different blockers, of which the doses were effective in preventing $\mathrm{P}$-induced gonadotropin release. After stimulation of the MPO, serum LH was significantly elevated 0.5 and $1.5 \mathrm{hr}$ later to the levels not different from those of control animals. However, the concentrations of serum LH in animals treated with pimozide or atropine $4.0 \mathrm{hr}$ after stimulation were significantly lower than those in the control group $(\mathrm{p}<0.05)$.

On the other hand, rats with electrochemical stimulation of the MPO showed

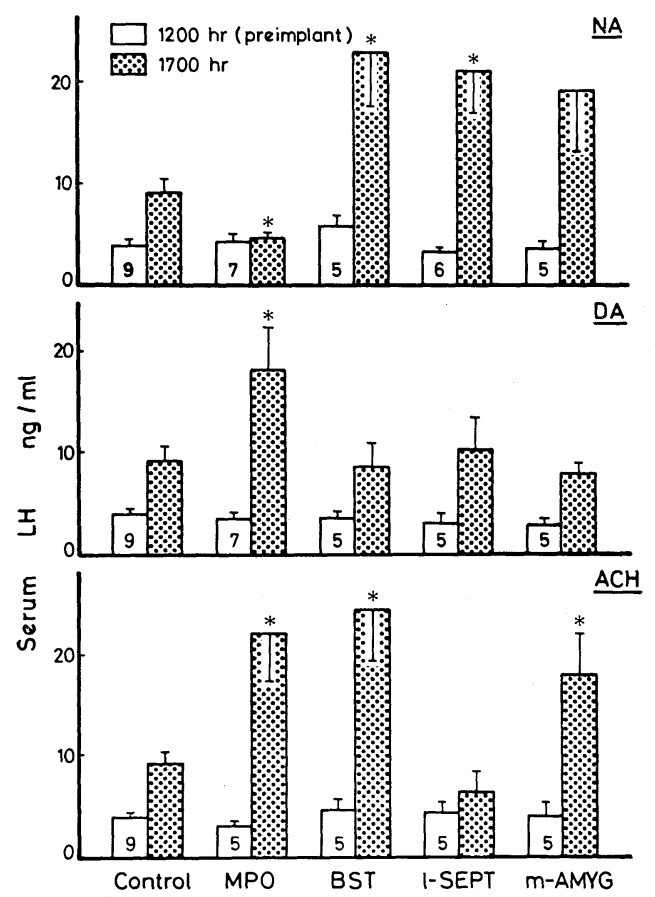

Fig. 3. Effects of intracerebral implantations of noradrenaline (NA), dopamine (DA) or acetylcholine $(\mathrm{ACH})$ on $\mathrm{LH}$ release in ovariectomized estradiol benzoate-primed rats. Each bar and the vertical line represent mean and the $S E M$, respectively. Values were obtained $30 \mathrm{~min}$ before implantation (at $1200 \mathrm{hr}$ ) and $5 \mathrm{hr}$ after implantation (at $1700 \mathrm{hr}$ ). The number of animals is given in the base of each column. Abbreviations used in this figure are BST, bed nucleus of the stria terminalis; m-AMYG, medial part of the amygdala! MPO, medial preoptic area; 1-SEPT, lateral part of the septum.

$* \mathrm{p}<0.05$ vs. control at $1700 \mathrm{hr}$. significantly higher concentrations of serum FSH than those of sham stimulated animals 1.5 and $4.0 \mathrm{hr}$ later $(\mathrm{p}<0.05)$ (Table 1$)$. Phenoxybenzamine, pimozide or atropine neither affected the prestimulation levels of serum FSH nor blocked the FSH release following the electrochemical stimulation of the MPO, which occurred 1.5 and $4.0 \mathrm{hr}$ later in control animals.

\section{Experiment III}

Although insertions of empty inner cannula into various parts of the brain of EBprimed rats through chronically implanted outer cannula induced a slight increase in serum LH $5 \mathrm{hr}$ later $(\mathrm{p}<0.01)$, no significant difference among the sites of implantation could be observed, thus the data were combined into one control group. DA or $\mathrm{ACH}$, when implanted into the MPO at $1200 \mathrm{hr}$ induced a significant increase in serum LH $5 \mathrm{hr}$ later $(\mathrm{p}<0.05$ or $\mathrm{p}<0.01$, respectively), whereas implantations of NA into the same area significantly reduced serum LH concentration as compared to the value obtained from the control group $(\mathrm{p}<0.05)$ (Fig. 3). Implantations of NA or $\mathrm{ACH}$, but not of DA into the BST were significantly effective in increasing serum LH $(\mathrm{p}<0.01)$, and the concentrations $5 \mathrm{hr}$ later rose above $20 \mathrm{ng} / \mathrm{ml}$. Furthermore, $\mathrm{ACH}$ implanted into the m-AMYG induced an $\mathrm{LH}$ release $(\mathrm{p}<0.05)$, and NA implantations tended to increase LH levels although they were not statistically significant $(p>0.05)$. The LH levels after DA implantations into this area did not differ from those of the control group. Among the implantations of NA, DA or $\mathrm{ACH}$ into the 1-SEPT, only NA implantations were effective in increasing serum $\mathrm{LH} 5 \mathrm{hr}$ later $(\mathrm{p}<0.01)$.

The locations of the implantation sites are shown in Fig. 4. 


\section{Discussion}

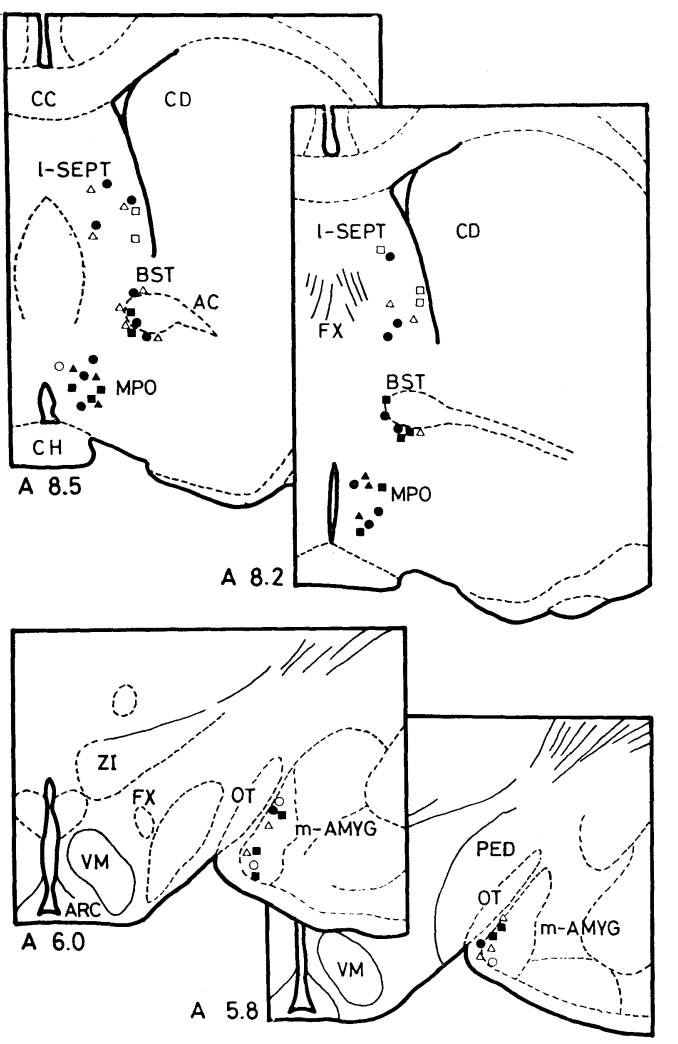

Fig. 4. Schematic illustrations showing the positions of intracerebral implantations. Circles, triangles and squares indicate that substances implanted were noradrenaline, dopamine and acetylcholine, respectively. Solid symbols represent effective sites inducing a significant change in serum LH concentration and open ones, ineffective sites. Abbreviations are AC, anterior commissure; ARC, arcuate nucleus; BST, bed nucleus of the stria terminalis; $\mathrm{CC}$, corpus callosum ; $\mathrm{CD}$, caudate nucleus; $\mathrm{CH}$, optic chiasma; $\mathrm{FX}$, fornix; 1-SEPT, lateral part of the septum ; mAMYG, medial part of the amygdala; MPO, medial preoptic area; OT, optic tract; PED, cerebral peduncle; VM, ventromedial nucleus; ZI, zona incerta.
Although numerous blockers of catecholamines and $\mathrm{ACH}$ are widely used to investigate their effects on brain functions, it should be mentioned, first of all, that none of blockers are completely specific. Indeed, even the receptor blockers employed in the present study have been shown to have central neural actions other than blocking respective receptors (Goodman and Gilman, 1975), but their actions seem to be relatively specific in the dose employed in this study.

The present experiment using monoaminergic and cholinergic blockers demonstrated that NA, DA and $\mathrm{ACH}$, all play, possibly as neurotransmitters, stimulatory roles in the regulation of $\mathrm{P}$-induced gonadotropin release in ovariectomized EB-primed rats. Phenoxybenzamine prevented P-induced gonadotropin release in ovariectomized EB-primed rats. $\alpha$-Blockers have been shown to inhibit coitus-induced ovulation in the rabbit (Sawyer et al., 1947), spontaneous ovulation in the rat (Everett et al., 1949) and the pulsatile release of LH in the ovariectomized rat (Gnodde and Schuiling, 1976). The same effects have been observed following administration of inhibitors of dopamine- $\beta$-hydroxylase, diethyldithiocarbamate (Kalra and McCann, 1974) or FLA 63 (Terasawa et al., 1975), which are known to decrease NA levels of the brain without altering DA levels.

On the other hand, pimozide, a potent dopamine receptor blocker, also blocked P-induced LH and FSH release. Among the studies using catecholamine synthesis blockers, there is an apparent disagreement concerning the role of DA in the regulation of gonadotropin secretion. Kordon and Glowinski (1969) reported that blockade of ovulation by the administration of $\alpha$-methyl$p$-tyrosine in PMS- and HCG-treated immature rats could be overcome by restora- 
tion of both brain NA and DA levels but not by that of NA level only, suggesting the stimulatory involvement of a dopaminergic mechanism in the regulation of $\mathrm{LH}$ release. Conversely, other investigators (Kalra and McCann, 1974) have suggested the involvement of NA but not of DA in $\mathrm{LH}$ release by applying a similar experimental method to proestrous rats. Furthermore, the inhibitory role of DA in LH release was proposed by other studies using DA release blocker (Gnodde and Schuiling, 1976) and DA receptor stimulants (Fuxe et al., 1975). The results of the present study using receptor blockers support the stimulatory role of DA in the regulation of $\mathrm{LH}$ release which is also shown by the present implantation experiments, although the differences of hormonal conditions of animals used should be taken into consideration.

Atropine was shown to completely prevent $\mathrm{P}$-induced gonadotropin release in ovariectomized EB-primed rats in the present study. Blocking effects of atropine on ovulation (Everett et al., 1949) and preovulatory release of LH, FSH and prolactin (Libertun and McCann, 1973) were also observed in proestrous rats. Moreover, it was demonstrated that cholinergic receptor blockers decreased plasma $\mathrm{LH}$ in ovariectomized rats (Libertun and McCann, 1973; Gnodde and Schuiling, 1976). Apparently, ACH plays a stimulatory role in the regulation of $\mathrm{LH}$ and FSH release.

Monoaminergic or cholinergic blockers, at a dose shown to block P-induced gonadotropin release following electrochemical stimulation of the MPO. On the basis of the present results it would seem most reasonable to propose that none of adrenergic, dopaminergic and cholinergic synapses are involved in mediating the effect of electrochemical stimulation of the MPO to the medial basal hypothalamus, and that electrochemical stimulation activates directly luteinizing hormone-releasing hormone ( $\mathrm{LH}-$ $\mathrm{RH}$ ) neurons or LH-RH containing neural elements in the MPO to induce discharge of LH-RH from the axon terminals in the median eminence into portal vessels. However, Rubinstein and Sawyer (1970) have shown that treatment with reserpine in proestrous female rats elevated the threshold for inducing ovulation by stimulation of the MPO but not of the median eminencearcuate nucleus region. Furthermore, Kalra and McCann (1973) demonstrated that the elevation in plasma $\mathrm{LH}$ following preoptic stimulation of rats was markedly inhibited by pretreatment with $\alpha$-methyl- $p$-tyrosine or a more specific NA synthesis blocker, diethyldithiocarbamate, suggesting that a noradrenergic synapse may lie between the MPO and median eminence. Our results were in disagreement with theirs. It is possible that the discrepancy could be due to the methodological problem, such as the differences in the strength of stimulation of the MPO or the mechanism of action of blockers used. However, the results reported here are consistent with the recent findings on the localization of the cell bodies of $\mathrm{LH}-\mathrm{RH}$ producing neurons. It was reported that the interruption of connection between the MPO and medial basal hypothalamus was followed by a marked decrease in the content of LH-RH (Weiner et al., 1975; Brownstein et al., 1976) or of immunoreactive LH-RH axons (Sétáló et al., 1976) in the medial basal hypothalamus, suggesting that a considerable portion of the LHRH neurons terminating in the median eminence have their cell bodies in the extrahypothalamic regions. Barry et al. (1973), demonstrated that cell bodies of LH-RH neurons were found in the septal, suprachiasmatic and parolfactory region. However, failure of blockers in inhibiting gonadotropin release induced by electrochemical stimulation of the MPO does not completely exclude the possibility of the concurrence of another mediating pathway, which proceeds from the MPO to synapse with LH-RH neurons in the medial basal hypo- 
thalamus. And the possible modulatory action of catecholaminergic and cholinergic neurons on the activity of LH-RH neurons by axo-axonic connections in the median eminence (Fuxe and Hökfelt, 1969) is not also excluded.

This is the first study that examined systematically the effects of the administration of $\mathrm{NA}, \mathrm{DA}$ and $\mathrm{ACH}$ into various discrete areas of the rat brain on $\mathrm{LH}$ release. Concerning the effects of implantations of catecholamines into the arcuate nucleusmedian eminence on ovulation, a few reports are available. Uemura and Kobayashi (1971) have shown that implantations of lower doses of DA into the median eminence, but not into other hypothalamic regions, inhibited ovulation and produced prolonged estrus, and implantations of the higher doses into the same area induced prolonged diestrus. Their suggestion of the inhibitory action of DA at the level of the median eminence was supported by the results of histochemical studies (Fuxe and Hökfelt, 1969; Löfström et al., 1977). In the present study, the inhibitory effect of DA implantations on $\mathrm{LH}$ release was not demonstrated in any locations examined, though DA implantation into the arcuate nucleus-median eminence was not attempted, but DA was shown to be effective in inducing $\mathrm{LH}$ release when implanted into the MPO. The preoptic anterior hypothalamic region was reported to receive an abundance of fibers from the incerto-hypothalamic dopaminergic system (Björklund et al., 1975). Our results may offer the possible explanation to the controversy concerning the role of DA in the regulation of gonadotropin secretion: Both in in vitro experiments and in experiments of intraventricular injection, DA might act on the MPO as well as the median eminence. If neurons in the MPO are mainly exposed to DA, LH surge may occur, and if the arcuate nucleusmedian eminence is mainly exposed, LH surge may not be induced or rather sup- pressed. The concept of this dual regulation of $\mathrm{LH}$ release by DA might be also aplicable to the explanation of results of Kamberi et al. (1970) that intraventricular injections of lower doses of DA induced LH release, but higher doses of DA inhibited the LH release. The site and dosage of administration in in vivo experiments and dissected area of hypothalamic fragment in in vitro experiments seem essential factors determining whether LH release is stimulated or inhibited.

The present experiment shows that NA implantations into the BST or 1-SEPT have a stimulatory effect on $\mathrm{LH}$ release while NA into the MPO has a inhibitory effect. Interestingly, both the BST and 1-SEPT are located within the area indispensable for the stimulatory feedback action of estradiol on LH release in EB-primed ovariectomized rats (Kawakami et al., 1978b). Furthermore, the MPO is a sensitive area to estrone. Thus, estrogen may modulate the responsiveness of NA sensitive neurons in these areas which regulate $\mathrm{LH}$ secretion. In addition, the effectiveness of NA implantations into the BST and 1-SEPT should be noted since it may be allowed to postulate that a large dose of NA injected into the third ventricle would have reached these neural structures to release $\mathrm{LH}$ in other studies (Sawyer et al., 1974; Kamberi et al., 1970 ; Tima and Flerkó, 1974). Furthermore, recent histochemical studies have shown that these neural structures are innervated by terminals from the ascending NA pathway originating in the brain stem (Fuxe and Hökfelt, 1969), and that NA terminals in the MPO may be concerned in the regulation of LH release (Löfström et al., 1977). The recent finding that lesions in the ventral NA pathway by microinjections of 6-hydroxydopamine blocked ovulation or P-induced gonadotropin release in ovariectomized rats (Martinovic and McCann, 1977) also suggests that these NA sensitive neural structures including the BST and 1-SEPT 
as well as the MPO play important roles in the regulation of gonadotropin secretion.

Effective sites of $\mathrm{ACH}$ implantations for inducing $\mathrm{LH}$ release were spread extensively. The present results are reasonably explained by the finding that $\mathrm{ACH}$ was able to release LH from the anterior pituitary gland incubated in vitro in the presence of rat hypothalamic fragments (Fiorindo and Martini, 1975). The same authors also reported that intraventricular injections of $\mathrm{ACH}$ induced a significant $\mathrm{LH}$ release in male rats (Justo et al., 1975). Additionally, our unpublished data that $\mathrm{ACH}$ implantations into the vicinity of one of the circumventricular organs, the organum vasculosum lamina terminalis, in which immunoreactive LH-RH has been found (Zimmerman et al., 1974), significantly increased serum $\mathrm{LH}$ suggest that $\mathrm{ACH}$ axons may terminate directly on LHRH containing elements in this region.

The concept is suggested by the present study that the neural regulation of gonadotropin secretion involves several synapses with different neurotransmitters in different areas. This concept may give possible explanations for the discrepancies concerning the role of NA, DA and $\mathrm{ACH}$ in the regulation of gonadotropin release. However, in order to clarify at which sites chemical substances are exerting their effects and which substance(s) is finally crucial for inducing LH-RH release, further studies are needed.

\section{Acknowledgements}

The authors thank Dr. A. F. Parlow and the Rat Pituitary Program of the National Institute of Arthritis, Metabolic and Digestive Diseases, U.S.A., for suppling radioimmunoassay kits, and Dr. K. Wakabayashi, Gunma University, for his help and advice in radioimmunoassays. This research was supported by Grant 248118 from the Ministry of Education, Science and Culture, Japan.

\section{References}

Albe-Fessard, D., F. Stutinsky and S. Libouban Atlas stéréotaxique du diencéphale du rat blanc, Centre National de la Recherche Scientifique, Paris (1966).

Barry, J., M. P. Dubois and P. Poulain (1973). Cell Tiss. Res. 146, 351.

Björklund, A., O. Lindvall and A. Nobin (1975). Brain Res. 89, 29.

Brownstein, M. J., A. Arimura, A. V. Schally, M. Palkovits and J. S. Kizer (1976). Endocrinology 98, 662.

Everett, J. W., C. H. Sawyer and J. E. Markee (1949). ibid. 44, 234.

Fiorindo, R. P. and L. Martin (1975). Neuroendocrinology 18, 322.

Fuxe, K. and T. Hökfelt Frontiers in Neuroendocrinology 1969 (edited by L. Martini and G. F. Ganong). Oxford University Press, London, p. 47 (1969).

Fuxe, K., L. F. Agnati, H. Corrodi, B. J. Everitt, T. Hökfelt, A. Löfström and U. Ungerstedt Advances in Neurology, Vol. 9 (edited by D. B. Calne, T. N. Chase and A. Barbeau). Raven Press, New York, p. 223 (1975).

Gnodde, H. P. and G. A. Schuiling (1976). Neuroendocrinology 20, 212.

Goodman, L. S. and A. Gilman The Pharmacological Basis of Therapeutics. 5th ed. MacMillan New York (1975).

Justo, G., M. Motta and L. Martini (1975). Experientia 31, 598.

Kalra, S. P. and S. M. McCann (1973). Endocrinology 93, 356.

Kalra, S. P. and S. M. McCann (1974). Neuro endocrinology 15, 79.

Kamberi, A. A., R. S. Mical and J. C. Porter (1970). Endocrinology 87, 1.

Kawakami, M., F. Kimura, M. Manaka and S. Kawagoe (1975). Endocrinol. Japon. 22, 549.

Kawakami, M and F. Kimura Subcellular Mechanisms in Reproductive Neuroendocrinology (edited by F. Naftolin, K. J. Ryan and J. Davis). Elsevier Scientific, Amsterdam, p. 423 (1976).

Kawakami, M., J. Arita, E. Yoshioka, S. Visessuvan and T. Akema (1978a). Endocrinology 103, 752.

Kawakami, M., E. Yoshioka, N. Konda, J. Arita and S. Visessuvan (1978b). ibid. 102, 701.

Kordon, C. and J. Glowinski (1969). ibid. 85, 924.

Krieg, R. J. and C. H. Sawyer (1976). ibid. 99, 411, Libertun, G. and S. M. McCann (1973). ibid. 92, 1714.

Löfström, A., P. Eneroth, J. E. Gustafsson and P. Skett (1977). ibid. 101, 1559.

Martinovic, J. V. and S. M. McCann (1977). ibid. 100, 1206. 
Miyachi, Y., R. S. Mecklenburg and M. B. Lipsett (1975). ibid. 93, 492.

Rotsztejn, W. H., J. L. Charli, F. Pattou and C. Kordon (1977). ibid. 101, 1475.

Rubinstein, L. and C. H. Sawyer (1970). ibid. 86, 988.

Sawyer, C. H. (1952). Anat. Rec. 112, 385.

Sawyer, C. H., J. E. Markee and W. H. Hollinshead (1947). Endocrinology 41, 395.

Sawyer, C. H., J. Hilliard, S. Kanematsu, R. Scaramuzzi and C. A. Blake (1974). Neuroendocrinology 15, 328.

Schneider, H. P. G. and S. M. McCann (1969). Endocrinology 85, 121.
Schneider, H. P. G. and S. M. McCann (1970). ibid. 86, 1127.

Sétáló, G., S. Vigh, A.V. Schally, A. Arimura and B. Flerkó (1976). Brain Res. 103, 597.

Terasawa, E., W. E. Bridson, J. W. Davenport and R. W. Goy (1975). Neuroendocrinology 18, 345.

Tima, L. and B. Flerkó (1974). ibid. 15, 346.

Uemura, H. and H. Kobayashi (1971). Endocrinol. Japon. 18, 91.

Weiner, R. I., E. Pattou, B. Kerdelhue and C. Kordon (1975). Endocrinology 97, 1597.

Zimmerman, E. A,. K. C. Hsu, M. Feirn and G. P. Kozlowski (1974). ibid. 95, 1. 